\title{
25-Hydroxyvitamin D and cognitive performance in mid-life
}

\author{
Jane Maddock ${ }^{1 *}$, Marie-Claude Geoffroy ${ }^{1}$, Chris Power ${ }^{1}$ and Elina Hyppönen ${ }^{1,2}$ \\ ${ }^{1}$ Centre for Paediatric Epidemiology and Biostatistics, UCL Institute of Child Health, 30 Guilford Street, \\ London WC1N 1EH, UK \\ ${ }^{2}$ School of Population Health, University of South Australia, Adelaide, Australia \\ (Submitted 31 January 2013 - Final revision received 30 July 2013 - Accepted 30 July 2013 - First published online 18 October 2013 )
}

\section{Abstract}

Hypovitaminosis D has been linked with poor cognitive function, particularly in older adults, but studies lack a lifespan approach; hence, the effects of reverse causality remain unknown. In the present study, we aimed to assess the relationship between 25 -hydroxyvitamin $\mathrm{D}$ $(25(\mathrm{OH}) \mathrm{D})$ concentrations and subsequent cognitive performance in mid-adulthood and the influence of earlier life factors, including childhood cognitive ability, on this association. Information for the present study was obtained from the members of the 1958 British birth cohort ( $n$ 6496). Serum 25(OH)D concentration, indicating vitamin D status, was measured at age 45 years. Verbal memory (immediate and delayed word recall), verbal fluency (animal naming) and speed of processing were tested at age 50 years. Information on childhood cognitive ability, educational attainment, vitamin D-related behaviours and other covariates was collected prospectively from participants throughout their life. Childhood cognitive ability and educational attainment by age 42 years were strongly correlated with cognitive performance at age 50 years and with several vitamin D-related behaviours in mid-adulthood, but not with 25(OH)D concentrations at age 45 years. Participants with both low $(<25 \mathrm{nmol} / \mathrm{l})$ and high $(\geq 75 \mathrm{nmol} / \mathrm{l}) 25(\mathrm{OH}) \mathrm{D}$ concentrations at age 45 years performed significantly worse on immediate word recall. The associations attenuated after adjustment for childhood cognitive ability, education, and socio-economic position; however, for the immediate word recall test, there was a non-linear association with $25(\mathrm{OH}) \mathrm{D}$ after further adjustment for obesity, menopausal status, smoking, alcohol consumption, physical activity and depressive symptoms at age 45 years $\left(P_{\text {curvature }}=0.01\right)$. The present study demonstrated that $25(\mathrm{OH}) \mathrm{D}$ concentrations were non-linearly associated with immediate word recall in mid-life. A clarification of the level of $25(\mathrm{OH}) \mathrm{D}$ concentrations that is most beneficial for predicting better cognitive performance in mid-life is required.

\section{Key words: 25-Hydroxyvitamin D: Vitamin D: Verbal memory: Speed of processing: Verbal fluency}

Strategies to reduce cognitive decline and/or to maximise cognitive function may be explored by examining modifiable factors at a time before age-related changes are fully established. Past studies have assessed the effects of physical activity and education ${ }^{(1)}$. Improving nutritional status could also be beneficial. Recently, vitamin $\mathrm{D}$ deficiency has been associated with reduced cognitive function ${ }^{(2)}$. The active hormonal form of vitamin D (1,25-dihydroxyvitamin D, calcitriol) has been implicated in brain development and function ${ }^{(3)}$. Nuclear vitamin D receptors, metabolites of vitamin D and enzymes required for bioactivation have been found in the brain and central nervous system, suggesting local synthesis ${ }^{(4)}$. Experimental studies have demonstrated that calcitriol may play a role in brain and neuronal development, increase nerve growth factor production ${ }^{(5,6)}$ and have neuroprotective potential and direct antioxidant effects ${ }^{(7-10)}$. Additionally, calcitriol may assist in the clearance of amyloid $\beta$ plaques ${ }^{(11)}$, protect against $\mathrm{Ca}$ toxicity $^{(12)}$ and mediate the risk of cerebrovascular conditions via its association with $\mathrm{CVD}^{(13)}$ and hypertension ${ }^{(14)}$. There is evidence among older adults that those with $<50 \mathrm{nmol} / 1$ of 25 -hydroxyvitamin D (25(OH)D, an indicator of vitamin D status) perform significantly worse on the Mini-Mental State Examination when compared with those with $\geq 50 \mathrm{nmol} / \mathrm{l}^{(2)}$. However, this relationship has not been consistent across all studies ${ }^{(15)}$.

Most studies to date have focused on older adult populations (age $\geq 65$ years), with some failing to adjust for potentially important confounding factors such as education and depressive symptoms ${ }^{(15)}$. Previous work has demonstrated that cognitive ability in childhood can protect against cognitive decline in mid-life ${ }^{(16)}$, and it could influence vitamin D-related behaviours such as use of supplements. However, childhood influences on the relationship between 25(OH)D concentrations and later cognitive ability have been largely overlooked. In the present study, we aimed to examine the association between $25(\mathrm{OH}) \mathrm{D}$ concentrations and subsequent

Abbreviations: 25(OH)D, 25-hydroxyvitamin D; SEP, socio-economic position.

*Corresponding author: J. Maddock, email jane.maddock.10@ucl.ac.uk 
performance on cognitive tests at age 50 years, a time when age-related changes in cognitive function are beginning to be established ${ }^{(16)}$, while taking account of factors such as educational attainment and childhood cognitive ability.

\section{Methods}

\section{Participants}

For the present study, information was obtained from the members of the 1958 British birth cohort, consisting of 18558 people (17634 from England, Scotland or Wales and
920 immigrants included up to age 16 years) born in March 1958 and followed from birth to age 50 years $^{(17)}$. The sample is broadly representative of the surviving cohort; however, it may slightly under-represent those in certain minority groups, those with behavioural problems and/or poorer cognitive ability at 7 years ${ }^{(18)}$. Information for the present study (Fig. 1) was collected in childhood (ages 7, 11 and 16 years) and adulthood (ages 23, 33, 42, 45, 46 and 50 years). The 45-year biomedical survey was approved by the South-East Multi-Centre Research Ethics Committee (reference 01/1/44), and written consent for use of information in medical research

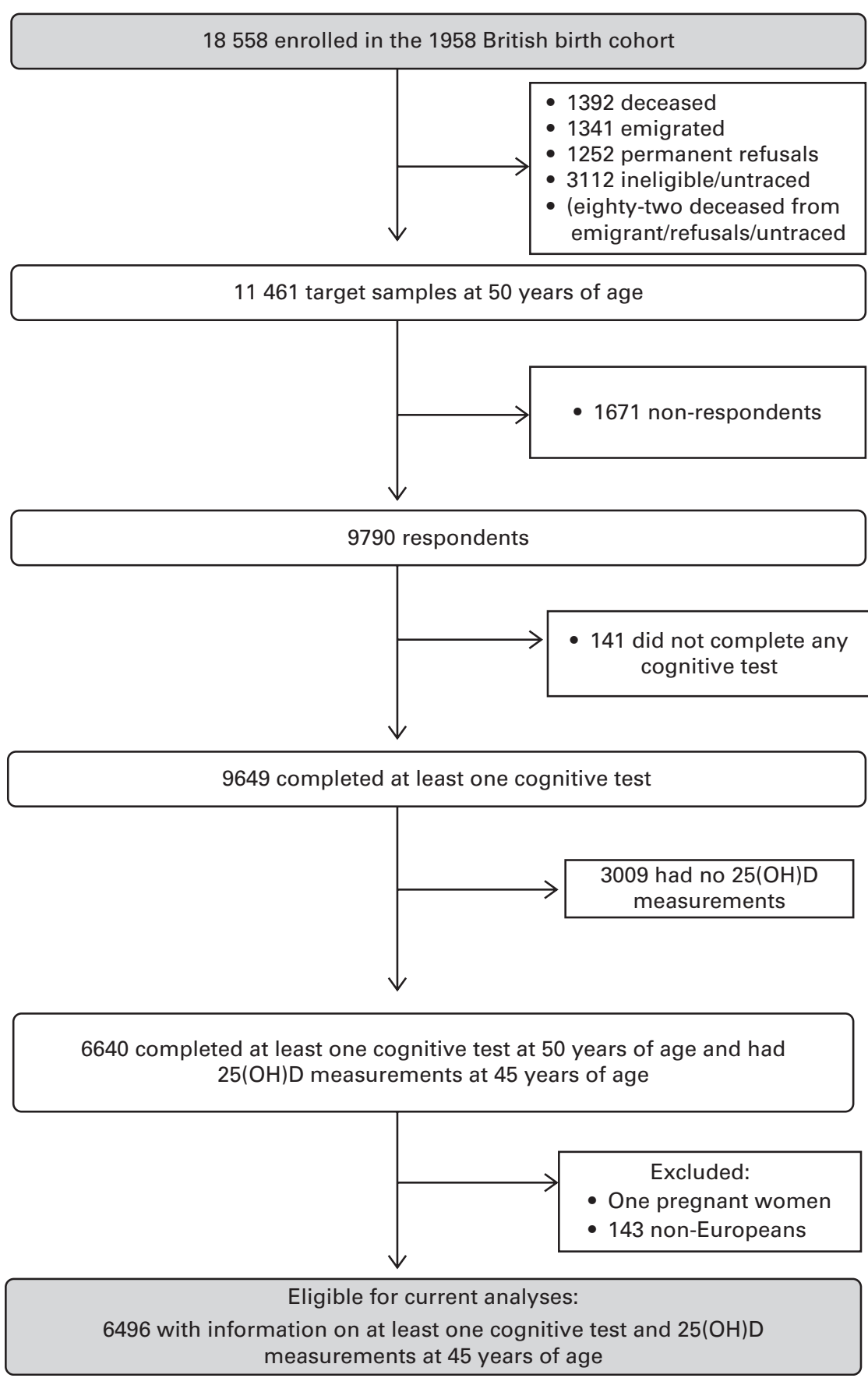

Fig. 1. Number of the participants of the 1958 British birth cohort and selection for the present study. 25(OH)D, 25-hydroxyvitamin D. 
studies was obtained from the participants. The present study was conducted according to the guidelines laid down in the Declaration of Helsinki.

\section{Vitamin D measurement at age 45 years}

A venous, non-fasting blood sample was collected from consenting participants (age 45 years) of a biomedical survey. The month of blood collection was recorded and categorised by season: winter (December-February); spring (March-May); summer (June-August); autumn (September-November). The samples were sent to the central laboratory (Royal Victoria Infirmary, Newcastle upon Tyne, UK) where vitamin D status (measured by $25(\mathrm{OH}) \mathrm{D}$ concentrations) was assessed. Serum $25(\mathrm{OH}) \mathrm{D}$ concentrations were measured using an automated Immunodiagnostic Systems Limited OCTEIA assay with a Dade-Behring BEP2000 analyser (Dade-Behring) and standardised according to the mean vitamin $\mathrm{D}$ external quality assessment scheme with a sensitivity of $5.0 \mathrm{nmol} / 1$, linearity $\leq 155 \mathrm{nmol} / 1$ and intra-assay CV 5.5-7.2\% ${ }^{(19)}$. The categorisation of $25(\mathrm{OH}) \mathrm{D}$ was based on previously established thresholds: $<25,25-49,50-74,75-99$ and $\geq 100 \mathrm{nmol} / \mathrm{l}^{(20,21)}$.

\section{Cognitive measures at age 50 years}

Cognitive performance, including two verbal memory tasks, one verbal fluency task and one speed of processing task, was assessed at the participant's home at age 50 years. Verbal memory was assessed using the immediate and delayed word recall tests. The former examined how many words a participant could immediately recall from a list of ten common words (e.g. book, tree; range 0-10). The latter examined how many of these words could be recalled (range $0-10$ ) after a short interval of approximately $5 \mathrm{~min}$, during which the other cognitive tests were conducted. A total of four word lists were randomly assigned. They were mainly read out by a computer voice; however, the interviewer read out the lists at an equivalent pace to the computer for $2 \%$ of cases. Verbal fluency was assessed using the animal-naming task in which participants named as many different animals as possible within $1 \mathrm{~min}$ (range 0-65). The letter cancellation $\operatorname{task}^{(22)}$ assessed speed of processing. Participants crossed out as many target letters ( $\mathrm{P}$ and $\mathrm{W}$ ) as possible within $1 \mathrm{~min}$ from a page incorporating 125 upper-case letters of the alphabet (range 84-780). These measures have been used in other longitudinal studies (e.g. the 1946 British birth cohort $^{(23)}$ and the English Longitudinal Study of Aging) ${ }^{(24)}$. Pearson's correlations between adulthood cognitive tests ranged from 0.08 to 0.65 ( $P<0.001$ for all).

Factors that may have influenced performance on cognitive tests were controlled for in the analyses. They included testing time of day and week (weekday morning, weekday afternoon, weekday evening, weekend morning, weekend afternoon or weekend evening), presence of others in the room (yes or no), administration of word list (computer voice or interviewer), word list ( $\mathrm{a}, \mathrm{b}, \mathrm{c}$ or $\mathrm{d}$ ) and other contextual factors affecting performance (yes or no) (see the footnote in Table 2).

\section{Educational attainment and cognitive measures in childhood}

Educational attainment (none or some qualifications, O-level (or equivalent), A-level (or equivalent) or higher degree) was based on the highest qualification obtained by age 42 years (or by age 33 years if data were missing).

Cognitive ability in childhood was assessed at ages 7, 11 and 16 years. Mathematics ability at age 7 years was assessed using ten problems with increasing levels of difficulty (range $0-10)^{(25)}$. Arithmetic tests at ages 11 years (range $0-40$ ) and 16 years (range $0-31$ ) were constructed specifically for use in the 1958 British birth cohort by the National Foundation for Educational Research in England and Wales and Manchester University, respectively. Reading ability was assessed using the Southgate test at age 7 years (range $0-30)^{(26)}$ and an assessment similar to the Watts-Vernon comprehension tests was constructed by the National Foundation for Educational Research in England and Wales at ages 11 and 16 years (range 0-35). A standardised test for general ability, consisting of verbal (range 0-40) and non-verbal (range 0-40) components, was conducted when the participants were aged 11 years ${ }^{(27)}$. Pearson's correlations between childhood tests ranged from 0.44 to $0.78(P<0.001$ for all).

The tests were standardised for age at assessment and averaged to obtain a summary score for childhood cognitive ability $^{(28)}$. Missing data on one test were replaced by that individual's mean standardised score on the other tests.

\section{Covariates}

Covariates identified as being potentially relevant included region of residence, socio-economic position (SEP) in childhood and adulthood ${ }^{(29)}, \mathrm{BMI}^{(30)}$, menopausal status ${ }^{(22)}$, smoking $^{(31)}$, alcohol consumption ${ }^{(32)}$, physical activity ${ }^{(33)}$ and depressive symptoms ${ }^{(34)}$.

Region of residence (Southern England and Channel Islands (South), Middle England and Wales (Middle), Northern England and Isle of Man (North) or Scotland) was self-reported at age 46 years. SEP was defined using the Registrar General's classification grouped into four categories: professional and managerial (I and II); non-manual (IIINM); manual (IIIM); unskilled (IV and V). SEP in childhood was based on father's occupation at birth (or at age 7 years if data were missing), and SEP in adulthood was assessed when the participants were aged 42 years. Smoking (never/former or current) and alcohol consumption (non-drinker, light drinker, moderate drinker, heavy drinker or very heavy drinker) were selfreported at ages 42 and 45 years, respectively. BMI at age 45 years was defined using the participant's weight in $\mathrm{kg}$ divided by height measured in $\mathrm{m}^{2}\left(\mathrm{~kg} / \mathrm{m}^{2}\right)$. Obesity was defined as BMI $\geq 30 \mathrm{~kg} / \mathrm{m}^{2(35)}$. Menopausal status was identified at age 45 years (postmenopausal, pre-menopausal or peri-menopausal), where men were coded separately. Frequency of physical activity was self-reported during an interview at age 42 years $(<1$ time per week, $2-3$ times per week or 4-7 times per week). Participants with two or more depressive symptoms were identified at age 45 years through 
a standardised, semi-structured interview (Clinical-Interview Schedule Revised). This test was administered by trained survey nurses visiting the participant's home, with the aim of assessing depressive symptoms in the past week ${ }^{(36)}$.

Self-reported vitamin D-related lifestyles at age 45 years included the following: frequency of consumption of oily fish (i.e. salmon, trout, mackerel, sardines or fresh tuna) and margarine (weekly or less than weekly) as well as supplements of cod-liver oil, fish oil or others containing vitamin D (daily or less than daily); amount of time spent outside during the past month and leisure time spent watching television or using a personal computer ( $\geq 3$ or $<3 \mathrm{~h} / \mathrm{d}$ ); frequency of sun-cover usage (most of the time or rarely); blistering after sun-burn (often, rarely, sometimes or never); seeking suntan (often, rarely, sometimes or never) ${ }^{(37)}$. The use of dietary supplements, i.e. pill powders, tablets or drops (yes or no), was also reported at age 45 years.

\section{Statistical analyses}

Eligible participants for the present study included those who had completed at least one cognitive test at age 50 years, had 25(OH)D measurements at age 45 years, were of a European ancestry and were not pregnant ( $n$ 6496) (Fig. 1). The study samples varied from 6378 for the letter cancellation test to 6496 for the animal-naming and immediate word recall tests.

The distribution of $25(\mathrm{OH}) \mathrm{D}$ concentrations was slightly left-skewed; therefore, geometric means are reported. Cognitive tests at age 50 years were standardised to $z$-scores whereby the mean was 0 and standard deviation was 1 . First, the distribution of $25(\mathrm{OH}) \mathrm{D}$ concentrations by covariates was displayed. Significant associations between 25(OH)D concentrations and covariates were determined using sex-adjusted linear regression models whereby natural logtransformed values of $25(\mathrm{OH}) \mathrm{D}$ were used. Second, mean performance on each cognitive test by $25(\mathrm{OH}) \mathrm{D}$ concentrations was obtained. Third, to examine the effect of educational attainment and cognitive ability in childhood on cognitive tests at age 50 years, sex-adjusted linear regression models were used. Fourth, logistic regression models, adjusted for sex and SEP in adulthood and childhood, were used to establish the association of childhood cognitive ability and educational attainment with vitamin D-related behaviours. Finally, linear regression models were used to examine the associations between categorised $25(\mathrm{OH}) \mathrm{D}$ concentrations ( $<25 \mathrm{nmol} / 1$ as the reference) and performance on standardised cognitive tests at age 50 years. These regression models were adjusted for (1) sex and measurement conditions (i.e. season of blood collection, day and time of cognitive testing, presence of others in the room, other contextual factors affecting cognitive performance (see the footnote in Table 2), word list and method of delivery), (2) social conditions and cognitive factors at earlier life stages (i.e. region, childhood and adult SEP, childhood cognition and educational attainment by age 42 years) and (3) physical status and lifestyles (i.e. obesity, menopausal status, smoking, alcohol consumption, physical activity and depressive symptoms). The association between $25(\mathrm{OH}) \mathrm{D}$ concentrations and letter cancellation scores varied by sex ( $\left.P_{\text {interaction }} 0.04\right)$; therefore, stratified analyses were undertaken. Curvature was assessed by including the quadratic term of $25(\mathrm{OH}) \mathrm{D}$ in the models. The models with curvature terms were used to predict the immediate word recall scores at age 50 years.

Inverse probability weighting, in relation to the surviving cohort at age 50 years ( $n$ 17 091), was used to adjust for selection bias during regression analyses. The probability of being in the study was estimated from the factors that have been identified previously as associated with attrition (i.e. sex, social class at birth, mathematics score, and internalising and externalising behaviours at age 7 years $)^{(18)}$ using logistic regression.

Of the eligible participants, $89 \cdot 1 \%$ ( $n$ 5791) also had complete data for all covariates. Missing values ranged from $0.35 \%$ ( $n$ 23) for alcohol consumption to $2 \cdot 34 \%(n 152)$ for smoking. To account for missing data on covariates, multiple imputation by chained equations was performed: twenty complete datasets were created. The results based on regression analyses using multiple imputation or weighted samples were similar to those conducted on complete cases. The imputed results are presented. All analyses were performed using STATA version 12 (StataCorp) ${ }^{(38)}$.

\section{Results}

Of the 6496 participants, $49 \cdot 5 \%$ were male. The mean $25(\mathrm{OH}) \mathrm{D}$ concentrations at age 45 years were higher for men $(53.6(95 \%$ CI $52 \cdot 8,54.4) \mathrm{nmol} / \mathrm{l})$ than for women $(51.6$ (95\% CI 50.7, 52.4) nmol/1, $P=0 \cdot 01)$. The mean performance at age 50 years was 6.6 (SD 1.5$)$ for the immediate word recall test, 5.5 (SD 1.8) for the delayed word recall test, 22.5 (SD 6.3) for the animal-naming test and 334.0 (SD 88.1) for the letter cancellation test.

The characteristics of the participants varied according to 25(OH)D concentrations. For example, those with $50-74.9 \mathrm{nmol} / 1$ of $25(\mathrm{OH}) \mathrm{D}$ were more likely to live in southerly regions, be in a higher SEP, had a non-obese BMI, were non-smokers and light drinkers and had less than two depressive symptoms (Table 1). The mean performance on each cognitive test according to $25(\mathrm{OH}) \mathrm{D}$ concentrations is presented in Table 2 .

The participants with higher educational attainment and increased cognitive ability in childhood performed better on all the cognitive tests at age 50 years $(\beta$-coefficients ranged from $0.07(95 \%$ CI $0.05,0.09)$ to $0.22(95 \%$ CI $0.20,0.24)$ and from $0.12(95 \%$ CI $0.09,0 \cdot 15)$ to 0.45 (95\% CI 0.43 , 0.48), respectively; $P<0.001$ for all, after adjustment for sex).

Childhood cognitive ability and educational attainment were associated with vitamin D-related behaviours in later life (age 45 years). The participants with higher cognitive scores in childhood (or higher educational attainment) spent less time outside, less time watching television or using a personal computer in their leisure time, used sun-cover more often, took more supplements and ate more oily fish than those with lower scores in childhood $(P \leq 0.02$ for all, after adjustment for sex and SEP in childhood and adulthood; Fig. 2). While all behaviours (except time spent outside, 
Table 1. Characteristics of the participants of the 1958 British birth cohort by 25 -hydroxyvitamin $\mathrm{D}(25(\mathrm{OH}) \mathrm{D})$ concentration $(\mathrm{nmol} / \mathrm{l})$ (Mean values and standard deviations or percentages)

\begin{tabular}{|c|c|c|c|c|c|c|c|}
\hline & $\begin{array}{c}\text { Total } \\
(n 6496)\end{array}$ & $\begin{array}{c}<25 \\
(n 481)\end{array}$ & $\begin{array}{l}25-49 \cdot 9 \\
(n 2177)\end{array}$ & $\begin{array}{l}50-74 \cdot 9 \\
(n 2381)\end{array}$ & $\begin{array}{l}75-99 \cdot 9 \\
(n 1047)\end{array}$ & $\begin{array}{c}\geq 100 \\
(n 410)\end{array}$ & $P^{\star}$ \\
\hline \multicolumn{8}{|c|}{ Sex and measurement conditions } \\
\hline \multicolumn{8}{|c|}{ Season of blood collection (\%) } \\
\hline Winter & 1098 & $36 \cdot 4$ & $24 \cdot 2$ & $12 \cdot 3$ & $6 \cdot 9$ & $7 \cdot 8$ & \multirow[t]{4}{*}{$<0.001$} \\
\hline Spring & 1363 & $39 \cdot 1$ & $30 \cdot 6$ & $16 \cdot 2$ & $9 \cdot 4$ & $6 \cdot 3$ & \\
\hline Summer & 1525 & 12.5 & $18 \cdot 6$ & 29.5 & $26 \cdot 7$ & $19 \cdot 3$ & \\
\hline Autumn & 2510 & $12 \cdot 1$ & $26 \cdot 7$ & $42 \cdot 0$ & $57 \cdot 1$ & $66 \cdot 6$ & \\
\hline \multicolumn{8}{|l|}{$\operatorname{Sex}(\%)$} \\
\hline Male & 3218 & $40 \cdot 3$ & $49 \cdot 8$ & $49 \cdot 6$ & $52 \cdot 2$ & $52 \cdot 2$ & \multirow[t]{2}{*}{0.001} \\
\hline Female & 3278 & $59 \cdot 7$ & $50 \cdot 2$ & $50 \cdot 4$ & 47.9 & $47 \cdot 8$ & \\
\hline \multirow{2}{*}{\multicolumn{8}{|c|}{$\begin{array}{l}\text { Social conditions and cognitive factors at } \\
\text { earlier life stages }\end{array}$}} \\
\hline & & & & & & & \\
\hline South & 2503 & 33.5 & 38.5 & 38.9 & $40 \cdot 3$ & $37 \cdot 8$ & \multirow[t]{4}{*}{$<0.001$} \\
\hline Middle & 1674 & $22 \cdot 9$ & $25 \cdot 7$ & $26 \cdot 7$ & $26 \cdot 6$ & $22 \cdot 0$ & \\
\hline North & 1692 & $26 \cdot 8$ & $24 \cdot 3$ & $25 \cdot 8$ & $26 \cdot 5$ & 34.6 & \\
\hline Scotland & 621 & $16 \cdot 8$ & 11.4 & 8.4 & 6.7 & $5 \cdot 4$ & \\
\hline \multicolumn{8}{|l|}{ SEP in adulthood (\%) } \\
\hline I or II & 2709 & $39 \cdot 3$ & 41.9 & $41 \cdot 8$ & 41.5 & 43.4 & \multirow[t]{5}{*}{0.06} \\
\hline IIINM & 1373 & $21 \cdot 2$ & $21 \cdot 4$ & $21 \cdot 8$ & $20 \cdot 3$ & $17 \cdot 8$ & \\
\hline IIIM & 1216 & $15 \cdot 6$ & $17 \cdot 6$ & 18.4 & $22 \cdot 2$ & $22 \cdot 0$ & \\
\hline IV and V & 976 & 18.5 & $15 \cdot 9$ & $15 \cdot 0$ & $12 \cdot 3$ & $13 \cdot 7$ & \\
\hline Other/unknown & 222 & $5 \cdot 4$ & $3 \cdot 3$ & $3 \cdot 1$ & 3.7 & $3 \cdot 2$ & \\
\hline \multicolumn{8}{|l|}{ SEP in childhood (\%) } \\
\hline I or II & 1259 & 14.4 & $20 \cdot 3$ & $20 \cdot 0$ & $19 \cdot 3$ & $17 \cdot 1$ & \multirow[t]{4}{*}{0.01} \\
\hline IIINM & 644 & $9 \cdot 2$ & 8.9 & $10 \cdot 0$ & 11.8 & 11.0 & \\
\hline IIIM & 3122 & $46 \cdot 6$ & $48 \cdot 6$ & $47 \cdot 3$ & 47.5 & $52 \cdot 9$ & \\
\hline IV and V & 1341 & $26 \cdot 0$ & $20 \cdot 4$ & $21 \cdot 0$ & $19 \cdot 0$ & $17 \cdot 6$ & \\
\hline Childhood cognition $†$ & 6428 & & & & & & \\
\hline Mean & & $0 \cdot 12$ & 0.14 & $0 \cdot 18$ & $0 \cdot 16$ & 0.08 & 0.27 \\
\hline SD & & 0.83 & 0.78 & 0.77 & 0.76 & 0.75 & \\
\hline \multicolumn{8}{|l|}{ Educational attainment (\%) } \\
\hline None & 504 & $12 \cdot 5$ & $8 \cdot 2$ & $7 \cdot 2$ & $7 \cdot 0$ & $5 \cdot 1$ & \multirow[t]{5}{*}{$0 \cdot 13$} \\
\hline Some qualifications & 898 & 14.4 & $13 \cdot 9$ & $14 \cdot 0$ & $12 \cdot 6$ & $15 \cdot 1$ & \\
\hline O-level (or equivalent) & 1835 & 24.5 & $28 \cdot 3$ & $27 \cdot 7$ & $30 \cdot 2$ & $30 \cdot 2$ & \\
\hline A-level (or equivalent) & 1077 & $16 \cdot 4$ & $14 \cdot 8$ & $17 \cdot 0$ & $18 \cdot 1$ & $20 \cdot 2$ & \\
\hline Degree & 2182 & $32 \cdot 2$ & 34.8 & $34 \cdot 1$ & $32 \cdot 2$ & $29 \cdot 3$ & \\
\hline \multicolumn{8}{|l|}{ Physical status and lifestyles } \\
\hline BMI $\left(\mathrm{kg} / \mathrm{m}^{2}\right)(\%)$ & & & & & & & \\
\hline$<30$ & 4920 & 63.6 & $69 \cdot 4$ & $78 \cdot 3$ & 83.3 & 89.5 & \multirow[t]{2}{*}{$<0.001$} \\
\hline$\geq 30$ & 1546 & $35 \cdot 6$ & $30 \cdot 0$ & 21.4 & $16 \cdot 3$ & $10 \cdot 0$ & \\
\hline Menopause (\%) & & & & & & & \\
\hline Pre-menopausal & 2099 & 64.5 & $64 \cdot 2$ & 63.4 & $64 \cdot 7$ & $64 \cdot 8$ & $<0.001 \ddagger$ \\
\hline Peri-menopausal & 601 & $15 \cdot 0$ & $20 \cdot 0$ & $19 \cdot 2$ & $15 \cdot 8$ & $15 \cdot 8$ & \\
\hline Postmenopausal & 123 & $6 \cdot 3$ & 3.7 & 3.3 & 3.6 & $4 \cdot 1$ & \\
\hline Other reasons & 388 & $10 \cdot 8$ & $10 \cdot 3$ & $12 \cdot 3$ & $14 \cdot 0$ & $13 \cdot 8$ & \\
\hline Physical activity (times/we & & & & & & & \\
\hline$\leq 1$ & 3323 & 59.5 & $55 \cdot 5$ & $49 \cdot 6$ & $44 \cdot 8$ & $43 \cdot 4$ & $<0.001$ \\
\hline $2-3$ & 1373 & $16 \cdot 6$ & $19 \cdot 0$ & $21 \cdot 1$ & $26 \cdot 3$ & $25 \cdot 1$ & \\
\hline $4-7$ & 1656 & $22 \cdot 0$ & 23.4 & $27 \cdot 2$ & $26 \cdot 2$ & $29 \cdot 3$ & \\
\hline Smoking (\%) & & & & & & & \\
\hline Never/former & 4911 & 59.5 & $74 \cdot 0$ & 78.5 & $78 \cdot 7$ & $78 \cdot 8$ & $<0.001$ \\
\hline Current & 1433 & 38.1 & 23.8 & $19 \cdot 4$ & $18 \cdot 4$ & $18 \cdot 8$ & \\
\hline Alcohol consumption (uni & & & & & & & \\
\hline Non-drinker & 371 & $9 \cdot 2$ & 7.4 & 4.9 & 3.7 & $2 \cdot 4$ & 0.002 \\
\hline Light $(<7)$ & 3123 & 49.5 & $48 \cdot 8$ & $48 \cdot 6$ & $46 \cdot 1$ & $44 \cdot 2$ & \\
\hline Moderate $(7-14)$ & 1660 & $19 \cdot 3$ & $23 \cdot 2$ & $27 \cdot 1$ & $28 \cdot 8$ & $28 \cdot 5$ & \\
\hline Heavy (14-21) & 735 & 8.5 & $10 \cdot 6$ & 11.3 & $13 \cdot 2$ & 13.7 & \\
\hline Very heavy $(>21)$ & 584 & $12 \cdot 5$ & $9 \cdot 7$ & $7 \cdot 6$ & $8 \cdot 2$ & $10 \cdot 7$ & \\
\hline Depressive symptoms (\% & & & & & & & \\
\hline$<2$ symptoms & 5990 & $86 \cdot 9$ & $91 \cdot 8$ & $92 \cdot 5$ & 93.9 & $94 \cdot 6$ & $<0.001$ \\
\hline$\geq 2$ symptoms & 481 & $12 \cdot 3$ & 8.0 & $7 \cdot 1$ & $5 \cdot 8$ & 4.9 & \\
\hline
\end{tabular}

SEP, socio-economic position; NM, non-manual; M, manual.

${ }^{*} P$ value for trend was obtained from the linear regression model adjusted for sex.

†Standardised summary score for childhood cognition (age 7-16 years).

$\ddagger P$ value was obtained from the log-likelihood ratio test. 
Table 2. Mean performance on cognitive tests by 25 -hydroxyvitamin $\mathrm{D}(25(\mathrm{OH}) \mathrm{D})$ status

(Mean values and standard deviations)

\begin{tabular}{|c|c|c|c|c|c|c|c|c|c|}
\hline & \multirow[b]{3}{*}{ Total $^{*}$} & \multicolumn{4}{|c|}{ Verbal memory } & \multirow{2}{*}{\multicolumn{2}{|c|}{$\begin{array}{c}\text { Verbal fluency } \\
\text { Animal } \\
\text { naming } \\
\text { (range 0-65) }\end{array}$}} & \multirow{2}{*}{\multicolumn{2}{|c|}{$\begin{array}{c}\begin{array}{c}\text { Speed of } \\
\text { processing }\end{array} \\
\begin{array}{c}\text { Letter } \\
\text { cancellation }\end{array} \\
\text { (range 84-780) }\end{array}$}} \\
\hline & & \multicolumn{2}{|c|}{$\begin{array}{c}\text { Immediate word } \\
\text { recall } \\
\text { (range } 0-10)\end{array}$} & \multicolumn{2}{|c|}{$\begin{array}{l}\text { Delayed word } \\
\text { recall } \\
\text { (range } 0-10 \text { ) }\end{array}$} & & & & \\
\hline & & Mean & SD & Mean & SD & Mean & SD & Mean & SD \\
\hline \multicolumn{10}{|c|}{$25(\mathrm{OH}) \mathrm{D}(\mathrm{nmol} / \mathrm{l})$} \\
\hline$<25$ & 481 & $6 \cdot 4$ & $1 \cdot 6$ & $5 \cdot 4$ & 1.9 & 21.5 & $6 \cdot 5$ & 335 & 94 \\
\hline $25-49 \cdot 9$ & 2177 & $6 \cdot 6$ & 1.5 & $5 \cdot 5$ & $1 \cdot 8$ & $22 \cdot 5$ & $6 \cdot 3$ & 329 & 83 \\
\hline $50-74.9$ & 2381 & $6 \cdot 7$ & 1.5 & 5.5 & 1.8 & $22 \cdot 6$ & $6 \cdot 5$ & 337 & 90 \\
\hline $75-99.9$ & 1047 & $6 \cdot 6$ & 1.4 & 5.5 & $1 \cdot 8$ & $22 \cdot 5$ & $5 \cdot 7$ & 335 & 86 \\
\hline$\geq 100$ & 410 & $6 \cdot 4$ & $1 \cdot 6$ & $5 \cdot 2$ & $1 \cdot 8$ & $22 \cdot 5$ & $6 \cdot 6$ & 333 & 91 \\
\hline
\end{tabular}

${ }^{*} n$ varies according to the test: 6469 for immediate word recall and animal naming; 6454 for delayed word recall; 6378 for letter cancellation.

where 'more' time spent outside is associated with higher $25(\mathrm{OH}) \mathrm{D}$ concentrations) are associated with a higher mean 25(OH)D concentration in mid-life (Table S1, available online; also see previous work using the 1958 British birth cohort $^{(37)}$ ), there was no association between childhood cognition (or educational attainment) and 25(OH)D concentrations at age 45 years.

Table 3 shows the relationship between 25(OH)D concentrations at age 45 years and performance on the cognitive tests at age 50 years. There was evidence of a non-linear association between $25(\mathrm{OH}) \mathrm{D}$ concentrations and immediate word recall $\left(P_{\text {curvature }}=0.01\right.$, for the final model; Fig. 3), with concentrations of both $<25$ and $\geq 75 \mathrm{nmol} / \mathrm{l}$ of $25(\mathrm{OH}) \mathrm{D}, 5$ years previously, being associated with worse performance and levels of approximately $50-75 \mathrm{nmol} / 1$ of $25(\mathrm{OH}) \mathrm{D}$ associated with better performance. Adjustment for

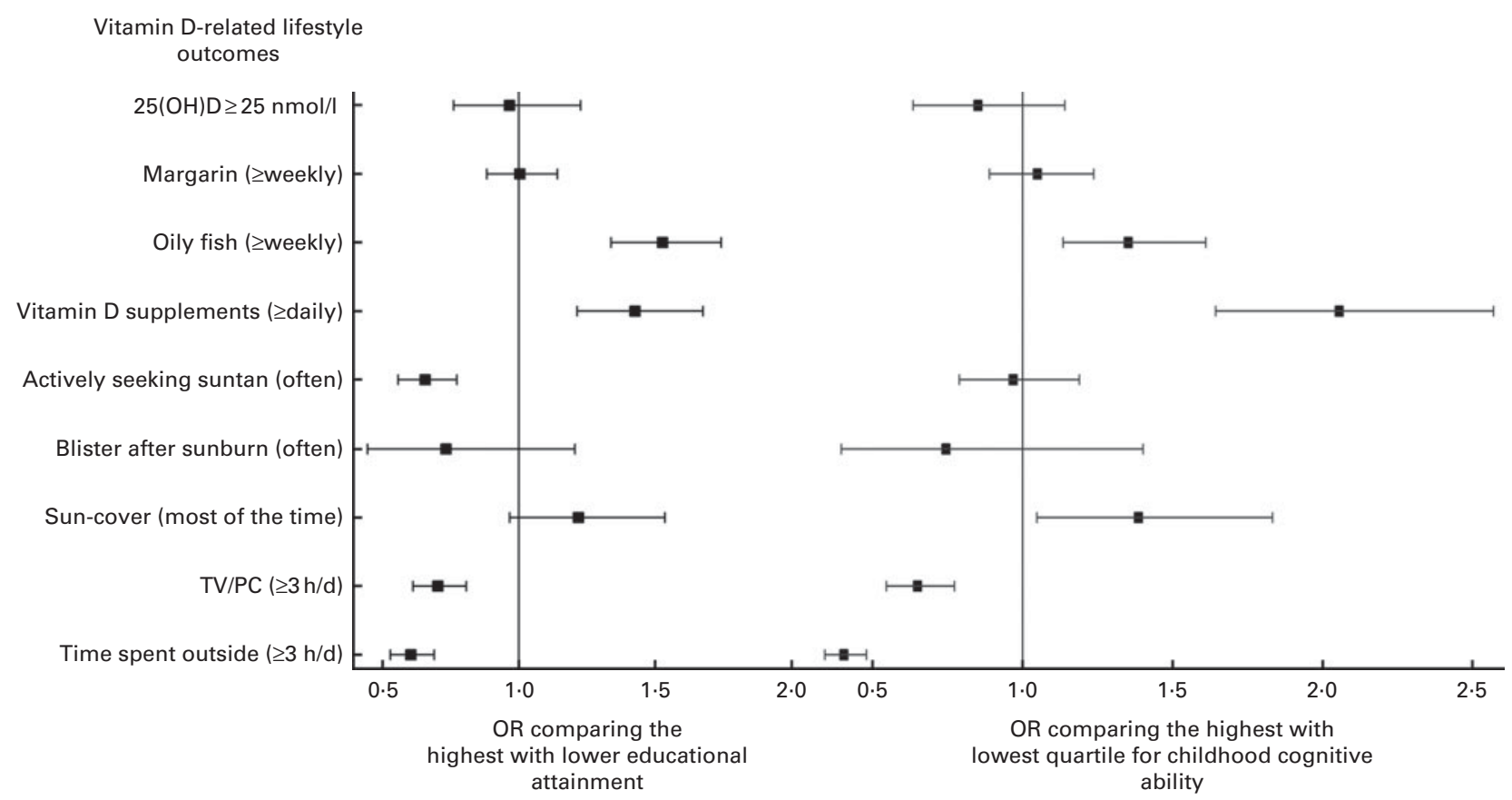

childhood cognitive ability and educational attainment weakened the non-linear relationship as did the further addition of lifestyle factors (i.e. obesity, menopausal status, smoking, alcohol consumption, physical activity and depressive symptoms) (Fig. 3). In fully adjusted models, no associations were observed for $25(\mathrm{OH}) \mathrm{D}$ concentrations and the delayed word recall, animal-naming task or letter cancellation score in men and women (Table 3). Additional adjustment for the use of general dietary supplements did not alter the estimates presented.

The link between higher 25(OH)D concentrations and improved cognitive function among older (age $>65$ years) adults has been tentatively suggested by previous studies ${ }^{(2)}$.

\section{Discussion}


Table 3. Linear regression modelling between 25 -hydroxyvitamin $\mathrm{D}(25(\mathrm{OH}) \mathrm{D})$ concentrations at age 45 years and cognitive function at age 50 years $(\beta$-Coefficients from the linear regression model and $95 \%$ confidence intervals)

\begin{tabular}{|c|c|c|c|c|c|c|c|c|c|c|c|}
\hline & \multicolumn{11}{|c|}{$25(\mathrm{OH}) \mathrm{D}(\mathrm{nmol} / \mathrm{l})$} \\
\hline & \multirow{2}{*}{$\frac{<25}{\beta}$} & \multicolumn{2}{|c|}{$25-49 \cdot 9$} & \multicolumn{2}{|c|}{$50-74.9$} & \multicolumn{2}{|c|}{$75-99.9$} & \multicolumn{2}{|c|}{$\geq 100$} & \multirow[b]{2}{*}{$P_{\text {trend }}$} & \multirow[b]{2}{*}{$P_{\text {curvature }}$} \\
\hline & & $\beta$ & $95 \% \mathrm{Cl}$ & $\beta$ & $95 \% \mathrm{Cl}$ & $\beta$ & $95 \% \mathrm{Cl}$ & $\beta$ & $95 \% \mathrm{Cl}$ & & \\
\hline \multicolumn{12}{|c|}{ Immediate word recall $(n 6496)^{\star}$} \\
\hline Model $1 \dagger$ & $1 \cdot 0$ & 0.12 & $0.02,0.21$ & 0.16 & $0.06,0.26$ & $0 \cdot 15$ & $0.04,0.26$ & -0.02 & $-0.16,0.11$ & 0.76 & $<0.001$ \\
\hline Model $2 \ddagger$ & 1.0 & 0.09 & $0.00,0.18$ & 0.12 & $0.02,0.21$ & $0 \cdot 11$ & $0.00,0.21$ & -0.03 & $-0.15,0.10$ & 0.88 & 0.001 \\
\hline Model $3 \S$ & 1.0 & 0.07 & $-0.02,0.16$ & 0.08 & $-0.01,0.18$ & 0.06 & $-0.04,0.17$ & -0.07 & $-0.20,0.06$ & 0.31 & 0.01 \\
\hline \multicolumn{12}{|c|}{ Delayed word recall $(n 6454)^{\star}$} \\
\hline Model $1 \dagger$ & 1.0 & 0.06 & $-0.04,0.16$ & 0.09 & $-0.01,0.19$ & 0.06 & $-0.05,0.17$ & -0.08 & $-0.21,0.05$ & 0.44 & 0.01 \\
\hline Model $2 \ddagger$ & $1 \cdot 0$ & 0.04 & $-0.05,0.13$ & 0.05 & $-0.04,0.15$ & 0.03 & $-0.07,0.14$ & -0.07 & $-0.20,0.05$ & 0.34 & $0 \cdot 10$ \\
\hline Model $3 \S$ & 1.0 & 0.03 & $-0.06,0.13$ & 0.04 & $-0.05,0.14$ & 0.02 & $-0.09,0.12$ & -0.08 & $-0.21,0.04$ & 0.22 & 0.14 \\
\hline \multicolumn{12}{|c|}{ Animal naming $(n \text { 6496) })^{*}$} \\
\hline Model $1 \dagger$ & $1 \cdot 0$ & 0.14 & $0.04,0.24$ & 0.17 & $0.07,0.27$ & $0 \cdot 14$ & $0.03,0.26$ & 0.16 & $0.03,0.30$ & 0.09 & 0.06 \\
\hline Model $2 \ddagger$ & 1.0 & 0.12 & $0.02,0.21$ & 0.12 & $0.02,0.21$ & 0.09 & $-0.02,0.19$ & 0.13 & $0.00,0.23$ & 0.38 & 0.34 \\
\hline Model $3 \S$ & 1.0 & 0.11 & $0.02,0.21$ & 0.11 & $0.01,0.21$ & 0.08 & $-0.03,0.19$ & 0.12 & $-0.01,0.25$ & 0.49 & 0.35 \\
\hline \multicolumn{12}{|c|}{ Letter cancellation (men) $(n 3156)^{*}$} \\
\hline Model $1 \dagger$ & 1.0 & -0.01 & $-0.16,0.14$ & 0.06 & $-0.09,0.21$ & $0 \cdot 10$ & $-0.07,0.26$ & 0.06 & $-0.13,0.26$ & 0.07 & 0.22 \\
\hline Model $2 \ddagger$ & $1 \cdot 0$ & -0.03 & $-0.18,0.12$ & 0.03 & $-0.12,0.18$ & 0.07 & $-0.09,0.24$ & 0.06 & $-0.13,0.26$ & 0.07 & 0.37 \\
\hline Model $3 \S$ & $1 \cdot 0$ & -0.04 & $-0 \cdot 18,0 \cdot 11$ & 0.02 & $-0.14,0.17$ & 0.07 & $-0.10,0.24$ & 0.06 & $-0.13,0.26$ & 0.07 & 0.51 \\
\hline \multicolumn{12}{|c|}{ Letter cancellation (women) $(n$ 3222)* } \\
\hline Model $1 \dagger$ & $1 \cdot 0$ & -0.05 & $-0.18,0.08$ & 0.04 & $-0 \cdot 10,0.17$ & -0.05 & $-0 \cdot 20,0.11$ & 0.01 & $-0.18,0.20$ & 0.70 & 0.24 \\
\hline Model 2‡ & $1 \cdot 0$ & -0.06 & $-0.19,0.08$ & 0.03 & $-0 \cdot 10,0 \cdot 17$ & -0.05 & $-0.20,0.11$ & 0.00 & $-0.19,0.20$ & 0.70 & 0.26 \\
\hline Model 3§ & 1.0 & -0.07 & $-0.20,0.07$ & 0.00 & $-0.14,0.14$ & -0.10 & $-0.25,0.07$ & -0.04 & $-0.24,0.15$ & 0.71 & 0.36 \\
\hline
\end{tabular}

$n$ represents the final model for imputed covariates. Outcomes were not imputed.

† Adjusted for sex, season, day and time of cognitive testing, presence of others in the room, other contextual factors affecting performance (i.e. blind or poor eyesight, deaf or hard of hearing, too tired, illness or physical impairment that affects the ability to perform, impaired concentration, very nervous or anxious, mental impairment, interruption or distraction, noisy environment, problems with the laptop or difficulty understanding English), word list and

† Additionally adjusted for region, socio-economic position (SEP) at age 42 years, SEP at birth (or at age 7 years if data were missing), childhood cognition and educational attainment by age 42 years.

$\S$ Additionally adjusted for obese BMI, menopausal status, smoking, alcohol consumption, physical activity and depressive symptoms at age 45 years. 


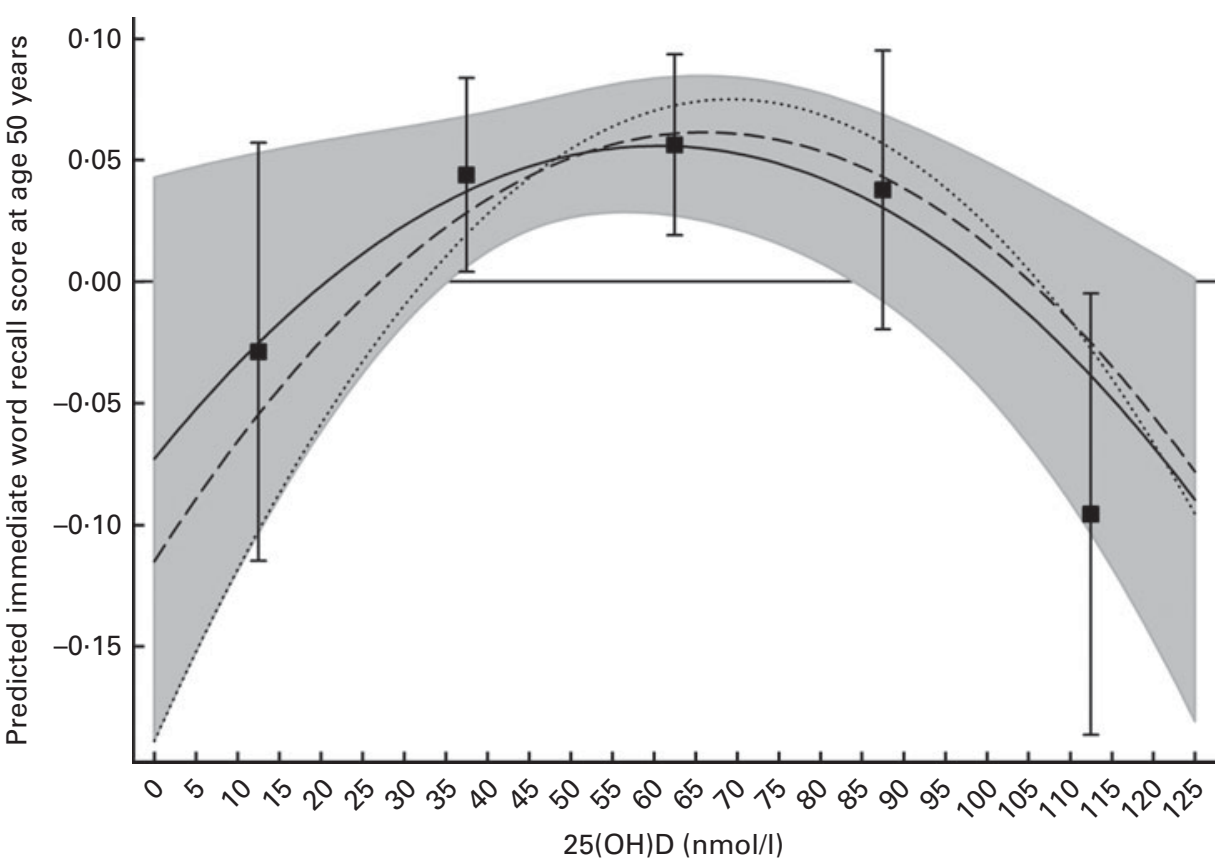

Fig. 3. Predicted immediate word recall (standardised) at 50 years of age according to 25 -hydroxyvitamin $\mathrm{D}(25(\mathrm{OH}) \mathrm{D}) \mathrm{concentrations}$ at 45 years of age. Values are predicted immediate word recall $(95 \%$ prediction interval $(\mathrm{PI})$ at 50 years of age for fully adjusted models. ........., Adjustment for sex, season, day and time of cognitive testing, presence of others in the room, other contextual factors affecting performance, word list and method of delivery. - -, Additional adjustment for region, socio-economic position (SEP) at 42 years of age, SEP at birth (or at 7 years of age if data were missing), childhood cognition and educational attainment by 42 years of age. __ Additional adjustment for obese BMI, menopausal status, smoking, alcohol consumption, physical activity and depressive symptoms at 45 years of age. The shaded areas indicate $95 \% \mathrm{PI}$ for fully adjusted models.

By using the data from a younger-aged adult population, the present study investigated the association between $25(\mathrm{OH}) \mathrm{D}$ concentrations and cognition at a life stage when cognitive decline is beginning to emerge. We found that $25(\mathrm{OH}) \mathrm{D}$ concentrations in the range of $50-75 \mathrm{nmol} / 1$ (37\% of participants) in mid-life (age 45 years) were associated with a better immediate word recall at age 50 years, while lower $(<25 \mathrm{nmol} / \mathrm{l})$ and higher $(\geq 75 \mathrm{nmol} / \mathrm{l}) \quad 25(\mathrm{OH}) \mathrm{D}$ concentrations were associated with reduced performance. This non-linear association between $25(\mathrm{OH}) \mathrm{D}$ concentrations and immediate word recall at age 50 years persisted after comprehensive adjustment for childhood cognition, education and other covariates. However, the magnitude of the association was small. No trends were found for $25(\mathrm{OH}) \mathrm{D}$ concentrations and other cognitive measures.

A recent meta-analysis demonstrated a $1.2(95 \%$ CI $0.5,1.9)$ improvement in scores on the Mini-Mental State Examination for the participants with $25(\mathrm{OH}) \mathrm{D}$ levels of $\geq 50 \mathrm{nmol} / 1 \mathrm{com}$ pared with those with $25(\mathrm{OH}) \mathrm{D}$ levels of $<50 \mathrm{nmol} / \mathrm{l}^{(2)}$; although, there was some heterogeneity between the studies. The present study differs in terms of age (50v $\geq 65$ years) and cognitive assessment (the Mini-Mental State Examination gives a global cognitive function score and can be used as a brief dementia-screening test $\left.{ }^{(39)}\right)$. However, a slight improvement $(\beta=0.08)$ in scores for the immediate word recall test was observed when the participants with $25(\mathrm{OH}) \mathrm{D}$ levels of $50-75 \mathrm{nmol} / 1$ were compared with those with $25(\mathrm{OH}) \mathrm{D}$ levels of $<25 \mathrm{nmol} / \mathrm{l}$.

Little is known about the relationship of vitamin D concentrations to different cognitive domains. Interestingly, although the immediate and delayed word recall tests were strongly correlated ( $r$ 0.7), no association between 25(OH)D concentrations and delayed recall was detected. This could be a chance finding or perhaps, in this age group, vitamin D is associated with measures of working memory (immediate word recall) rather than with those of short-term memory (delayed word recall). No association was found between $25(\mathrm{OH}) \mathrm{D}$ concentrations and the other cognitive domains assessed (i.e. verbal fluency and speed of processing); which were weakly correlated with verbal memory. Also, in a previous study conducted in an older adult population (age 65-99 years) in the USA, 25(OH)D was associated only with non-memory domains (i.e. executive function and speed of processing) ${ }^{(40)}$. Interpretation of these associations can be considered in two ways. First, vitamin D may have a specialised role in specific brain functions. Second, the association between vitamin $\mathrm{D}$ and other cognitive domains may vary by life stage. If the latter is true, the associations between $25(\mathrm{OH}) \mathrm{D}$ concentrations and other cognitive domains in the participants of the present study could manifest at later ages.

Although the decline in memory is steeper among older adults $^{(41)}$, it has been shown in mid-life ${ }^{(16)}$. Additionally, several studies investigating the impact of risk factors on cognitive decline and dementia over the life course have implied that certain mid-life factors may be particularly relevant for later cognitive functioning ${ }^{(42)}$. Therefore, studies such as the present one that investigate the role of vitamin $\mathrm{D}$ in cognitive function at a time point where age-related decline is just becoming apparent are essential for informing the timing and nature of potential interventions ${ }^{(43)}$. To our knowledge, 
only one previous study has investigated a younger adult population $^{(15)}$. This cross-sectional study examined three age groups: adolescents (age 12-17 years); younger adults (age 20-60 years); older adults (age 60-90 years). No association between low 25(OH)D concentrations and impaired performance on psychometric measures assessing memory and speed of processing was observed for younger adults; this category encompassed a wide age range, which reduces comparability to the present study, in which cognitive function was assessed at a specific age (50 years).

The debate regarding 'optimal' $25(\mathrm{OH}) \mathrm{D}$ concentrations has traditionally been in the context of optimising bone health ${ }^{(20)}$. While 25(OH)D levels of $<25 \mathrm{nmol} / 1$ are considered to be deficient, optimal concentrations remain unknown ${ }^{(21)}$. The non-linear association between $25(\mathrm{OH}) \mathrm{D}$ concentrations and cognitive performance observed is not unique to the present study. For instance, two studies used spline regression to demonstrate a reduction in cognitive function at lower $25(\mathrm{OH}) \mathrm{D}$ concentrations. Of these studies, one suggested that a reduction was most evident at $25(\mathrm{OH}) \mathrm{D}$ levels of $<35 \mathrm{nmol} / \mathrm{l}^{(44)}$, while the other proposed that improvement in cognitive function plateaus as $25(\mathrm{OH}) \mathrm{D}$ concentrations increased $^{(45)}$. This non-linear association with a suggestive threshold effect may have been overlooked in earlier studies and could be a crucial feature of the relationship between vitamin $\mathrm{D}$ and cognitive function that needs to be taken into account if trials are conducted in the future.

Another noteworthy finding from the present study involved early life variables. Childhood cognitive ability is strongly related to cognitive function in later life ${ }^{(16)}$. Therefore, we examined whether the association between $25(\mathrm{OH}) \mathrm{D}$ concentrations and cognitive function in mid-life was due to childhood cognition and/or educational attainment. We found that higher childhood cognitive ability and educational attainment are associated with behaviours that may predispose to higher vitamin D-related lifestyles in later life. Although childhood ability and educational attainment did explain a large proportion of the association between $25(\mathrm{OH}) \mathrm{D}$ concentrations and cognitive function in mid-life, the non-linear relationship persisted despite controlling for these factors. Therefore, vitamin D status may, to a small degree, predict overall cognitive ability and performance on immediate word recall at age 50 years.

Results should be interpreted with limitations in mind. Only one measurement of $25(\mathrm{OH}) \mathrm{D}$ was available, and it is possible that participants changed behaviour (and consequently their vitamin D status) during the 5-year interval. Therefore, inferences about the association between chronic or concurrent hypovitaminosis $\mathrm{D}$ and cognitive performance should be made with caution. The 50-year tests enable the investigation into the association of $25(\mathrm{OH}) \mathrm{D}$ concentrations with specific cognitive functions; however, an overall cognitive score was not available. Additionally, the influence of childhood cognitive ability on the subsequent association between $25(\mathrm{OH}) \mathrm{D}$ concentrations and cognitive function may have been underestimated due to differing measures of cognition in childhood and adulthood.
The major strengths of the present study include the large, nationwide population-based sample that enables the detection of small associations, as well as the novel focus of cognitive function in a younger adult age group than that used in most previous studies and the examination of the effect of earlier life factors. The present study included a comprehensive list of potential confounding variables not always available in previous studies. Analyses were restricted to the participants of European decent; therefore, the present results may not apply to non-white ethnic groups. Although some attrition was evident, previous work has indicated that the sample remains broadly representative of the white British population ${ }^{(18)}$. While comparing complete case results with the results that were weighted for sample attrition, no difference was observed.

The findings from the present study, using information from a mid-adulthood population, suggest that, although effect sizes are small, both low and high 25(OH)D concentrations are associated with poorer verbal memory as indicated by the immediate word recall in mid-life. Childhood cognition and educational attainment appear to contribute to this association, but do not fully explain it. Further examination to identify the $25(\mathrm{OH}) \mathrm{D}$ concentrations that predict better cognitive performance and explore potential threshold effects is required to clarify the observed association. Investigation is also necessary to establish causality of the association.

\section{Supplementary material}

To view supplementary material for this article, please visit http://dx.doi.org/10.1017/S0007114513003176

\section{Acknowledgements}

We are grateful to all the participants of the 1958 British birth cohort. We acknowledge Professor Ian Gibb, Dr Steve Turner and Marie-Claude Fawcett (Royal Victoria Infirmary, Newcastle upon Tyne, UK) for carrying out the laboratory assays and the Centre for Longitudinal Studies, Institute of Education (original data producers), for providing the data.

J. M. holds a UCL Impact studentship. M.-C. G. holds a postdoctoral fellowship from the Canadian Institutes of Health Research. The Medical Research Council funded the 2002-4 clinical follow-up of the 1958 British birth cohort (grant no. G0000934) and 25(OH)D assays were funded by the BUPA Foundation. Further support was obtained from the Jeans for Genes, the UK Medical Research Council (grant no. G0601653 and SALVE/PREVMEDSYN with Academy of Finland). The present study was undertaken at the Centre for Paediatric Epidemiology and Biostatistics, which benefits from funding support from the MRC in its capacity as the MRC Centre of Epidemiology for Child Health. Research at the University College London Institute of Child Health and Great Ormond Street Hospital for Children NHS Trust benefits from R\&D funding received from the NHS Executive. All the aforementioned funders had no role in the design, analysis or writing of this article. 
All authors contributed to the design, interpretation and critical revision of the manuscript. E. H. initiated and supervised the study and shared the primary responsibility with J. M. All authors approved the final manuscript.

None of the authors has any conflict of interest.

\section{References}

1. Kramer AF, Bherer L, Colcombe SJ, et al. (2004) Environmental influences on cognitive and brain plasticity during aging. J Gerontol A Biol Sci Med Sci 59, M940-M957.

2. Balion C, Griffith LE, Strifler L, et al. (2012) Vitamin D, cognition, and dementia: a systematic review and meta-analysis. Neurology 79, 1397-1405.

3. McCann JC \& Ames BN (2008) Is there convincing biological or behavioral evidence linking vitamin D deficiency to brain dysfunction? FASEB J 22, 982.

4. Eyles DW, Smith S, Kinobe R, et al. (2005) Distribution of the vitamin $\mathrm{D}$ receptor and 1 alpha-hydroxylase in human brain. J Chem Neuroanat 29, 21-30.

5. Eyles D, Brown J, Mackay-Sim A, et al. (2003) Vitamin $\mathrm{D}_{3}$ and brain development. Neuroscience 118, 641-653.

6. Brown J, Bianco JI, McGrath JJ, et al. (2003) 1,25-Dihydroxyvitamin $\mathrm{D}(3)$ induces nerve growth factor, promotes neurite outgrowth and inhibits mitosis in embryonic rat hippocampal neurons. Neurosci Lett 343, 139-143.

7. Oermann E, Bidmon HJ, Witte OW, et al. (2004) Effects of 1alpha, 25 dihydroxyvitamin D3 on the expression of HO-1 and GFAP in glial cells of the photothrombotically lesioned cerebral cortex. J Chem Neuroanat 28, 225-238.

8. Brewer LD, Thibault V, Chen KC, et al. (2001) Vitamin D hormone confers neuroprotection in parallel with downregulation of L-type calcium channel expression in hippocampal neurons. J Neurosci 21, 98-108.

9. Moore M, Piazza A, McCartney Y, et al. (2005) Evidence that vitamin $\mathrm{D}_{3}$ reverses age-related inflammatory changes in the rat hippocampus. Biochem Soc Trans 33, 573-577.

10. Bao BY, Ting HJ, Hsu JW, et al. (2008) Protective role of 1 alpha, 25-dihydroxyvitamin D3 against oxidative stress in nonmalignant human prostate epithelial cells. Int $J$ Cancer 122, 2699-2706.

11. Dursun E, Gezen-Ak D \& Yilmazer S (2011) A novel perspective for Alzheimer's disease: vitamin D receptor suppression by amyloid- $\beta$ and preventing the amyloid- $\beta$ induced alterations by vitamin $\mathrm{D}$ in cortical neurons. JAD 23, 207-219.

12. Brewer LD, Porter NM, Kerr DS, et al. (2006) Chronic $1 \alpha$, $25-(\mathrm{OH}) 2$ vitamin $\mathrm{D}_{3}$ treatment reduces $\mathrm{Ca}^{2+}$-mediated hippocampal biomarkers of aging. Cell Calcium 40, 277-286.

13. Wolf PA (2009) Stroke risk profiles. Stroke 40, S73-S74.

14. Barnard K \& Colon-Emeric C (2010) Extraskeletal effects of vitamin D in older adults: cardiovascular disease, mortality, mood, and cognition. Am J Geriatr Pharmacother 8, 4-33.

15. McGrath J, Scragg R, Chant D, et al. (2007) No association between serum 25-hydroxyvitamin D3 level and performance on psychometric tests in NHANES III. Neuroepidemiology 29, 49-54.

16. Richards M, Shipley B, Fuhrer R, et al. (2004) Cognitive ability in childhood and cognitive decline in mid-life: longitudinal birth cohort study. BMJ 328, 552 .

17. Power C \& Elliott J (2006) Cohort profile: 1958 British birth cohort (National Child Development Study). Int J Epidemiol 35, 34-41.

18. Atherton K, Fuller E, Shepherd P, et al. (2008) Loss and representativeness in a biomedical survey at age 45 years:
1958 British birth cohort. J Epidemiol Community Health 62, 216-223.

19. Hyppönen E, Turner S, Cumberland P, et al. (2007) Serum 25-hydroxyvitamin D measurement in a large population survey with statistical harmonization of assay variation to an international standard. J Clin Endocrinol Metab 92 , $4615-4622$.

20. Institute of Medicine (2011) Dietary Reference Intakes for Calcium and Vitamin D. Washington, DC: Institute of Medicine.

21. Lanham-New SA, Buttriss JL, Miles LM, et al. (2011) Proceedings of the rank forum on vitamin D. Br J Nutr 105, 144-156.

22. Richards M, Kuh D, Hardy R, et al. (1999) Lifetime cognitive function and timing of the natural menopause. Neurology 53 308.

23. Wadsworth M, Kuh D, Richards M, et al. (2006) Cohort Profile: the 1946 National Birth Cohort (MRC National Survey of Health and Development). Int J Epidemiol 35, 49-54.

24. Llewellyn DJ, Lang IA, Langa KM, et al. (2008) Cognitive function and psychological well-being: findings from a population-based cohort. Age Ageing 37, 685-689.

25. Pringle M, Butler N \& Davie R (1966) 11,000 Seven Year Olds. London: Longman, in association with National Children's Bureau.

26. Southgate V (1962) Southgate Group Reading Tests: Manual of Instructions. London: University of London Press.

27. Douglas J (1964) The Home and the School. London: MacGibbon and Kee.

28. Geoffroy M, Hertzman C, Li L, et al. (2012) Morning salivary cortisol and cognitive function in mid-life: evidence from a population-based birth cohort. Psychol Med 42, 1763.

29. Luo Y \& Waite LJ (2005) The impact of childhood and adult SES on physical, mental, and cognitive well-being in later life. J Gerontol Ser B Psychol Sci Soc Sci 60, S93-S101.

30. Corley J, Gow AJ, Starr JM, et al. (2010) Is body mass index in old age related to cognitive abilities? The Lothian Birth Cohort 1936 Study. Psychol Aging 25, 867-875.

31. Rohleder N \& Kirschbaum C (2006) The hypothalamicpituitary-adrenal (HPA) axis in habitual smokers. Int $J$ Psychophysiol 59, 236-243.

32. Anttila T, Helkala EL, Viitanen M, et al. (2004) Alcohol drinking in middle age and subsequent risk of mild cognitive impairment and dementia in old age: a prospective population based study. BMJ 329, 539.

33. Rovio S, Kåreholt I, Helkala EL, et al. (2005) Leisure-time physical activity at midlife and the risk of dementia and Alzheimer's disease. Lancet Neurol 4, 705-711.

34. Jorm AF (2000) Is depression a risk factor for dementia or cognitive decline? A review. Gerontology 46, 219-227.

35. National Health Service. (2010) Diagnosing obesity. Directgov. http://www.nhs.uk/Conditions/Obesity/Pages/Diagnosis. aspx (cited 1 May 2012).

36. Lewis G, Pelosi AJ, Araya R, et al. (1992) Measuring psychiatric disorder in the community: a standardized assessment for use by lay interviewers. Psychol Med 22, 465-486.

37. Hyppönen E \& Power C (2007) Hypovitaminosis D in British adults at age $45 \mathrm{y}$ : nationwide cohort study of dietary and lifestyle predictors. Am J Clin Nutr 85, 860-868.

38. StataCorp L (2011) Stata Statistical Software: Release 12. College Station, TX: StataCorp L.

39. Folstein MF, Folstein SE \& McHugh PR (1975) "Mini-mental state". A Practical Method for grading the cognitive state of patients for the clinician. J Psychiatr Res 12, 189-198. 
40. Buell JS, Scott TM, Dawson-Hughes B, et al. (2009) Vitamin D is associated with cognitive function in elders receiving home health services. J Gerontol A Biol Sci Med Sci 64, 888-895.

41. Hedden T \& Gabrieli JD (2004) Insights into the ageing mind: a view from cognitive neuroscience. Nat Rev Neurosci 5, 87-96.

42. Fratiglioni L, Mangialasche F \& Qiu C (2010) Brain aging: lessons from community studies. Nutr Rev 68, S119-SS27.
43. Salthouse TA (2009) When does age-related cognitive decline begin? Neurobiol Aging 30, 507-514.

44. Lee DM, Tajar A, Ulubaev A, et al. (2009) Association between 25-hydroxyvitamin D levels and cognitive performance in middle-aged and older European men. J Neurol Neurosurg Psychiatry 80, 722-729.

45. Breitling LP, Perna L, Muller H, et al. (2012) Vitamin D and cognitive functioning in the elderly population in Germany. Exp Gerontol 47, 122-127. 